\title{
The Failure of Operation for Spinal Dural Arteriovenous Fistula Demonstrated by Intraoperative Indocyanine Green Video- Angiography
}

\author{
Seong $\mathrm{Yi}^{1}$ \\ 1. Department of Neurosurgery, Yonsei University \\ $\square$ Corresponding author: Seong Yi, yiseong@gmail.com \\ Disclosures can be found in Additional Information at the end of the article
}

\section{Abstract}

Our objective was to both describe and show (via video) the use of intraoperative indocyanine green (ICG) video-angiography for obliteration of a spinal dural arteriovenous fistula (DAVF).

ICG video-angiography is an emerging tool for delineating intraoperative vascular anatomy with significant potential in the treatment of vascular diseases in the spine.

The authors presented the case of a 49-year-old woman with progressive and debilitating bilateral lower-extremity weakness. The patient was diagnosed with a spinal AVM of the 10th thoracic vertebra based on the results of conventional spinal angiography.

The patient underwent T8-9 laminotomy for microsurgical clip occlusion. Intraoperative ICG video-angiography was used before clip placement to identify the arterialized veins of the fistula, as well as after clip placement to confirm obliteration of the fistulous connection. The authors failed to restore the normal blood flow through repeated temporary clip and ICG angiography.

In conclusion, intraoperative ICG video-angiography serves an important role in the microsurgical treatment of DAVF. It is simple process that provides real-time information regarding both the precise location of spinal DAVF and the result of spinal DAVF obliteration. The lack of understanding of anomalous vascular anatomy could be the cause of failure.

Received 08/29/2014 Review began 08/29/2014 Review ended 09/16/2014 Published 09/17/2014

C Copyright 2014

Yi. This is an open access article distributed under the terms of the Creative Commons Attribution License CC-BY 3.0., which permits unrestricted use, distribution, and reproduction in any medium, provided the original author and source are credited.
Categories: Radiology, Neurosurgery

Keywords: spinal dural arteriovenous fistula, icg video-angiography, indocyanine green, failure, operation

\section{Introduction}

Spinal vascular malformations represent around 2-4\% of all spinal diseases, and spinal dural arteriovenous fistulae (DAVFs) are the most common among them [1-3]. These lesions are vascular abnormalities in which a pathological arteriovenous shunt is located in the dural leaflets, typically at the intervertebral foramen [4-5]. Neurological impairment from spinal DAVFs is attributed to arterialization of intramedullary veins with subsequent venous hypertension; it can also be attributed to infarction in some cases [6-7]. 


\section{Cureus}

Treatment of spinal DAVFs requires interruption at the arteriovenous transition point, either by surgical clip occlusion or endovascular embolization. Intraoperative vascular imaging is a useful technique that can provide precise vascular anatomy and flow dynamics of the involved vessels. Indocyanine green (ICG) video-angiography has been used to assess vessel patency and aneurysm occlusion, to detect residual nidus in cerebral arteriovenous malformations, and to demonstrate extracranial-intracranial bypass patency [8-13].

With the advance of therapeutic modality, the success rate of treatment has increased thus far; however, we experienced the failure of complete occlusion of the DAVF when using ICG video angiography. We present a case of failure when using ICG video-angiography in the microsurgical treatment of symptomatic spinal DAVFs.

\section{Case Presentation}

A 49-year-old woman presented with eight months of paresthesia and hypoesthesia below the L2 level, a two-week history of progressive bilateral lower-extremity weakness, numbness, and urination/defecation difficulty. The patient was diagnosed with an uterine myoma and underwent laparoscopic radio frequency ablation under spinal anesthesia one year earlier. On neurological examination, motor grade in her both lower extremities was Grade 4 . Knee jerks were slightly increased. Informed patient consent was obtained for treatment.

The patient underwent a thoracic spinal MRI that showed swollen conus medullaris with a T2 signal increase and venous hypertension due to spinal DAVF and dilated perimedullary veins (Figure 1).

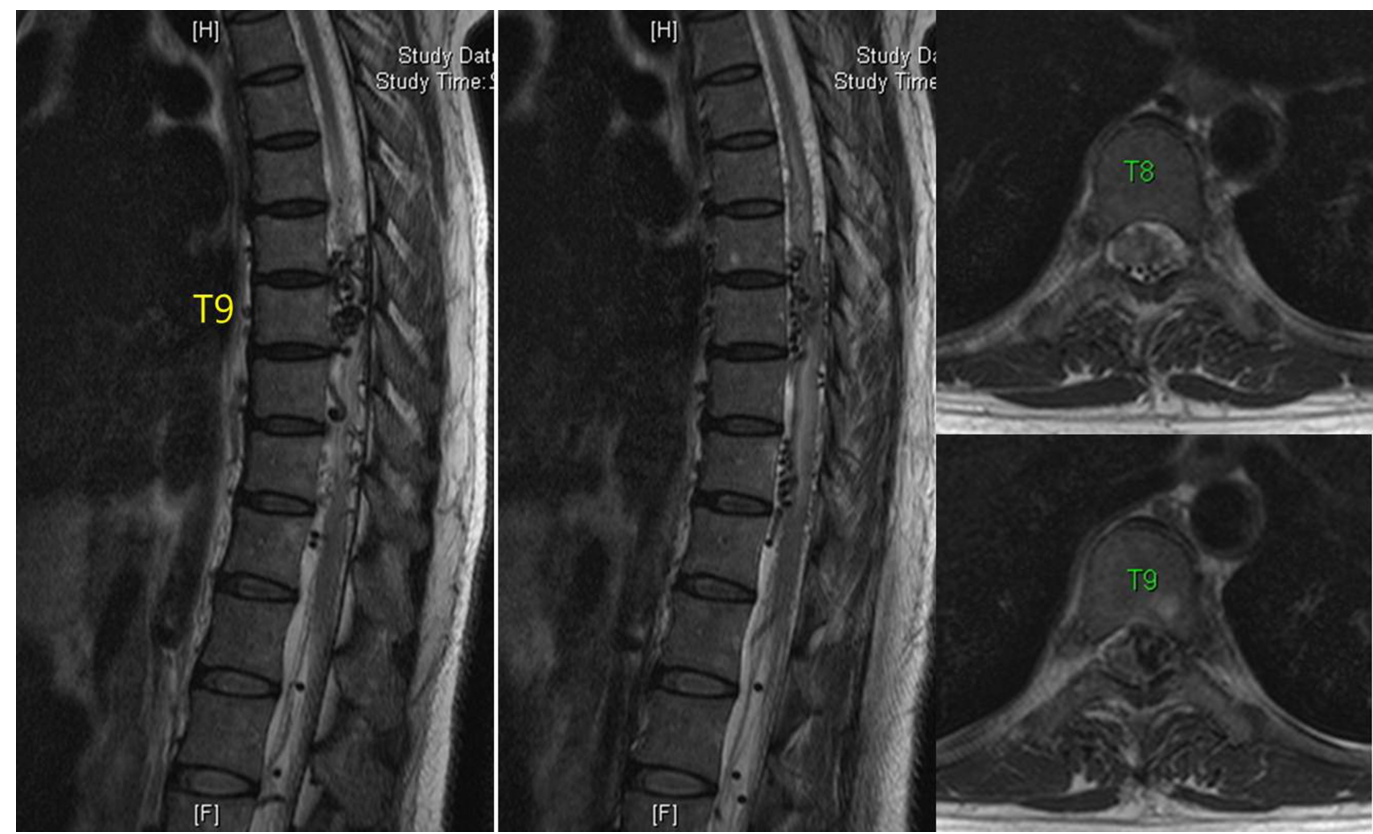

FIGURE 1: Spinal MRI shows swollen conus medullaris with a T2 signal increase and venous hypertension due to spinal DAVF and dilated perimedullary veins

On spinal angiography, spinal AVM at the T8-9 level fed by branches of left T8, T9, T10, and T11 intercostal segmental arteries, mainly T8-9 (Figure 2). 


\section{Cureus}
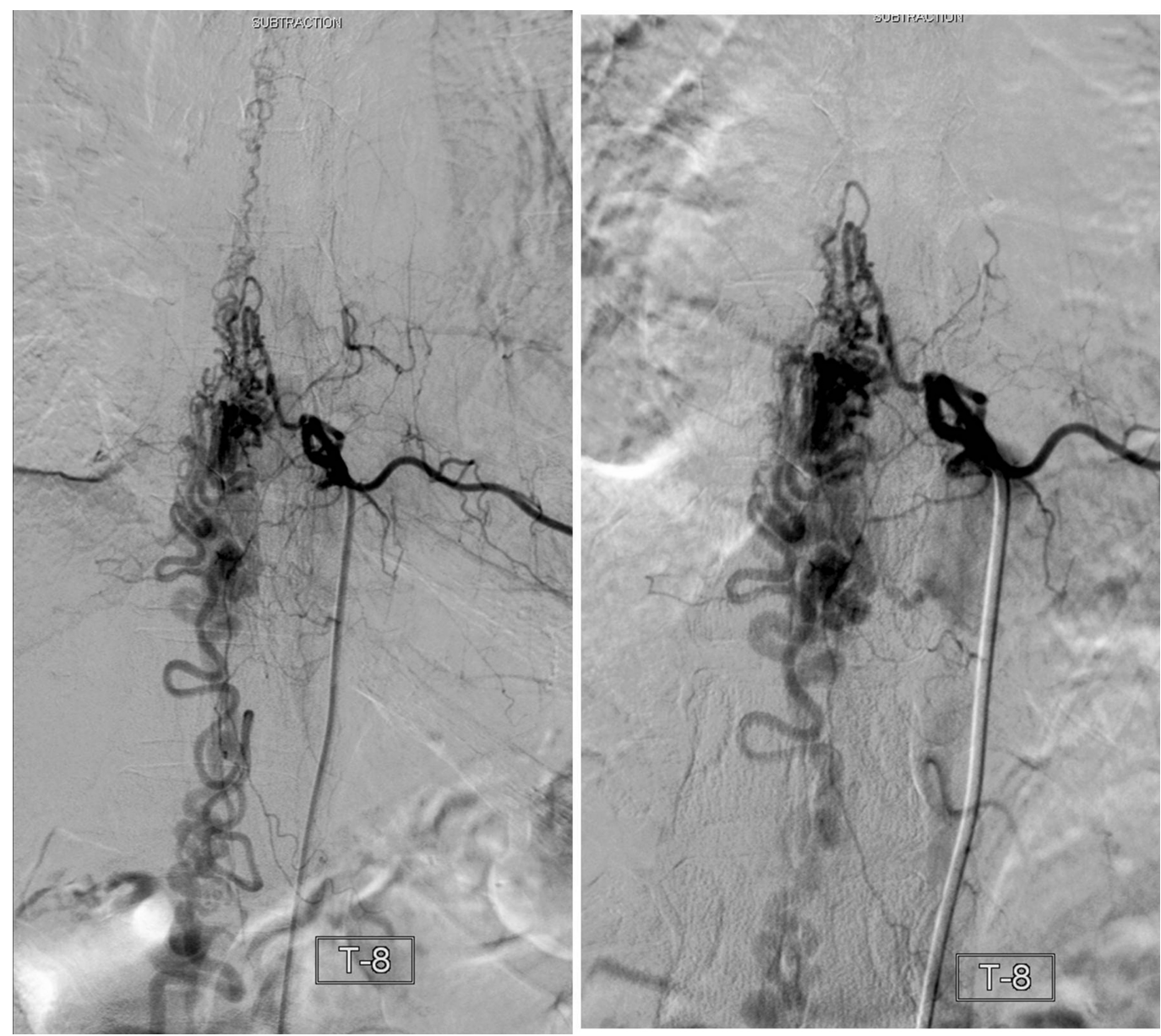

FIGURE 2: On spinal angiography, spinal AVM at the T8-9 level fed by branches of left T8, T9, T10, and T11 intercostal segmental arteries, mainly T8-9.

Endovascular embolization was tried at once. For embolization, superselection of the feeding vessel was done using Prowler 10-90' and Traxcess microwire from the origin of T9 intercostal artery. However, due to vessel tortuosity, distal advancing of microcatheter was not possible, and embolization therefore could not be carried out. Subsequently, a surgical method was chosen as the definitive treatment plan for this patient.

\section{Operation}

According to the reconstruction of preoperative spinal angiography, the AVM shunting point was on the pedicle`s level of T10 and located ventrally from the spinal cord. The patient underwent eighth and ninth level thoracic laminotomies for microsurgical clip occlusion of the feeding artery. The OPMI Pentero microscope, adapted with integrated fluorescence module infrared 800 (Carl Zeiss Co. Ltd, Oberkochen, Germany), was used. On the opening of the dura midline, abnormal arterialized veins were initially identified. Using ICG video-angiography, these vessels were confirmed to be arterialized veins based on the observation of rapid filling in the arterial phase. After applying a temporary clip to multiple feeding arteries point, ICG videoangiography was repeated with an interval to confirm reduction of the flow. Then, the temporary clip was replaced with a permanent clip. 


\section{Cureus}

\section{VIDEO 1: Surgical finding using intraoperative indocyanine green (ICG) video-angiography for obliteration of a spinal dural arteriovenous fistula (DAVF)}

View video here: https://vimeo.com/104707176

We tried to apply multiple clips for the feeding artery, but no combination of clips could obliterate the abnormal flow completely.

After the operation, spinal angiography was done, postoperative clinical status of the patient was unchanged, and motor weakness of the lower extremities progressed with two years of follow-up duration (Figure 3).
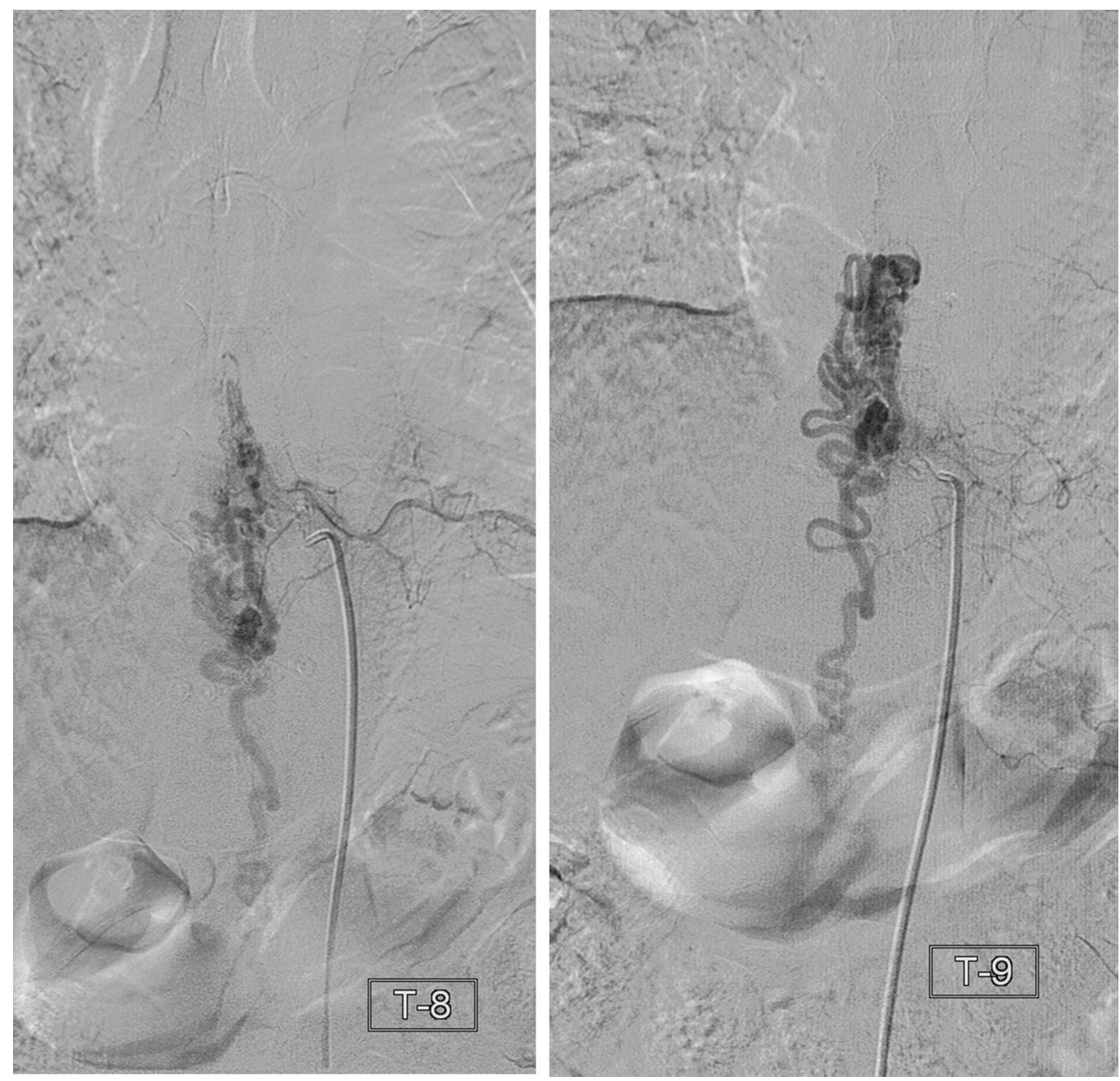

FIGURE 3: Postoperative spinal angiography

\section{Discussion}

Spinal DAVFs are common spinal vascular malformations. Spinal DAVF can lead to myelopathy or paraplegia if left untreated. In these times, the treatment of choice is endovascular instead of microsurgical obliteration of the fistula, if possible. The major challenge associated with 
microsurgical treatment is accurate intraoperative identification of the lesion and confirmation of its obliteration [14].

ICG video-angiography is a helpful tool in vascular procedures for intraoperative real time assessment of the local circulation. The absorption and emission peaks of ICG (805 and $835 \mathrm{~nm}$, respectively) lie within the "optical window" of tissue, where absorption attributable to endogenous chromophores is low. Within 1 to 2 seconds of intravenous injection, ICG primarily binds to globulins ( $\alpha 1$-lipoproteins), and remains within the vasculature. ICG is excreted exclusively by the liver with a plasma half-life of 3 to 4 minutes. It is not reabsorbed by the intestine, and the dose for ICG video-angiography is 0.2 to $0.5 \mathrm{mg} / \mathrm{kg}$; maximal daily dose should not exceed $5 \mathrm{mg} / \mathrm{kg}$. The technique of ICG video-angiography has been adapted to neurosurgical applications [9].

The only advantage of intraoperative spinal angiography would be in potentially providing a complete picture of the circulation in the operative field, whereas the ICG technique demonstrates only the vessels visible to the naked eye [15].

However, ICG is noninvasive and considered quite safe, so it can be repeated as needed without associated morbidity [11]. There is no radiation hazard, and it does not require another medical instrument, like a C-arm fluoroscopy. Furthermore, it is very easy to use ICG videoangiography, so it can reduce operation time. Finally, because ICG video-angiography is real time imaging, we can get rapid feedback for vascular intervention to prevent spinal cord ischemic damage.

A limitation of this technique is that only vessels visualized in the surgical field and only those not obstructed by clots, calcification, or atherosclerosis can be observed during angiography [11]. Therefore, ICG video-angiography cannot replace spinal angiography entirely. Another limitation is the difficulty in identifying the feeding artery and draining vein because of the presence of multiple dilated veins in the dural space and multiple shunts. Intraoperative direct ICG injection into the feeding artery via prepositioned angiographic catheter would be an option for proper visualization [16]. Intraoperative direct ICG injection could localize the exact fistula portion by minimizing the influence of normal arterial vasculature simultaneously enhanced by conventional peripheral venous ICG injection.

Intraoperative ICG video-angiography serves an important role in the microsurgical treatment of DAVF. It is simple and provides real-time information about the precise location of spinal DAVF and result after obliteration of spinal DAVF.

Though the intraoperative ICG video-angiography could be a tremendous help for identifying vascular structure and results of surgery in real time, total understanding of vascular flow in the anomalous vasculature is prerequisite for the success of operation. Attempts to obliterate this patient's AVM by placing multiple clips using ICG angiography failed.

\section{Conclusions}

The spinal AVF treatment examined in this report ultimately failed. Intraoperative ICG videoangiography serves an important role in the microsurgical treatment of DAVF. It is simple and provides real-time information about the precise location of spinal DAVF. To accomplish successuful treatment, all spinal angiography, intraoperative ICG angiography, and surgical findings should be considered. The lack of understanding of the anomalous vascular anatomy could be the cause of failure in this case.

\section{Additional Information}




\section{Disclosures}

Human subjects: Consent was obtained by all participants in this study. Conflicts of interest: In compliance with the ICMJE uniform disclosure form, all authors declare the following:

Payment/services info: All authors have declared that no financial support was received from any organization for the submitted work. Financial relationships: All authors have declared that they have no financial relationships at present or within the previous three years with any organizations that might have an interest in the submitted work. Other relationships: All authors have declared that there are no other relationships or activities that could appear to have influenced the submitted work.

\section{References}

1. Du J, Ling F, Chen M, Zhang H: Clinical characteristic of spinal vascular malformation in pediatric patients. Childs Nerv Syst. 2009, 25:473-8. 10.1007/s00381-008-0737-y

2. Steinmetz MP, Chow MM, Krishnaney AA, Andrews-Hinders D, Benzel EC, Masaryk TJ, Mayberg MR, Rasmussen PA: Outcome after the treatment of spinal dural arteriovenous fistulae: a contemporary single-institution series and meta-analysis. Neurosurg. 2004, 55:7787.

3. Spetzler RF, Detwiler PW, Riina HA, Porter RW: Modified classification of spinal cord vascular lesions. J Neurosurg. 2002, 96:145-56.

4. Anson JA, Spetzler RF: Interventional neuroradiology for spinal pathology . Clin Neurosurg. 1992, 39:388-417.

5. Rosenblum B, Oldfield EH, Doppman JL, Di Chiro G: Spinal arteriovenous malformations: a comparison of dural arteriovenous fistulas and intradural AVM's in 81 patients. J Neurosurg. 1987, 67:795-802.

6. Hurst RW, Kenyon LC, Lavi E, Raps EC, Marcotte P: Spinal dural arteriovenous fistula: The pathology of venous hypertensive myelopathy. Neurology. 1995, 45:1309-13.

7. Klopper HB, Surdell DL, Thorell WE: Type I spinal dural arteriovenous fistulas: Historical review and illustrative case. Neurosurg Focus. 2009, 26:E3. 10.3171/FOC.2009.26.1.E3

8. Imizu S, Kato Y, Sangli A, Oguri D, Sano H: Assessment of incomplete clipping of aneurysms intraoperatively by a near-infrared indocyanine green-video angiography (Niicg-Va) integrated microscope. Minim Invasive Neurosurg. 2008, 51:199-203. 10.1055/s-2008-1080916

9. Raabe A, Beck J, Gerlach R, Zimmermann M, Seifert V: Near-infrared indocyanine green video angiography: a new method for intraoperative assessment of vascular flow. Neurosurg. 2003, 52:132-9.

10. Raabe A, Beck J, Seifert V: Technique and image quality of intraoperative indocyanine green angiography during aneurysm surgery using surgical microscope integrated near-infrared video technology. Zentralbl Neurochir. 2005, 66:1-6.

11. Raabe A, Nakaji P, Beck J, Kim LJ, Hsu FP, Kamerman JD, Seifert V, Spetzler RF: Prospective evaluation of surgical microscope-integrated intraoperative near-infrared indocyanine green videoangiography during aneurysm surgery. J Neurosurg. 2005, 103:982-9.

12. Takagi Y, Kikuta K, Nozaki K, Sawamura K, Hashimoto N: Detection of a residual nidus by surgical microscope-integrated intraoperative near-infrared indocyanine green videoangiography in a child with a cerebral arteriovenous malformation. J Neurosurg. 2007, 107:416-8. 10.3171/PED-07/11/416

13. Woitzik J, Horn P, Vajkoczy P, Schmiedek P: Intraoperative control of extracranialintracranial bypass patency by near-infrared indocyanine green videoangiography. J Neurosurg. 2005, 102:692-8.

14. Vougioukas VI, Coulin CJ, Shah M, Berlis A, Hubbe U, Van Velthoven V: Benefits and limitations of image guidance in the surgical treatment of intracranial dural arteriovenous fistulas. Acta Neurochir (Wien). 2006, 148:145-53.

15. Hettige $\mathrm{S}$, Walsh D: Indocyanine green video-angiography as an aid to surgical treatment of spinal dural arteriovenous fistulae. Acta Neurochir (Wien). 2010, 152:533-6. 10.1007/s00701009-0445-8

16. Yano S, Hida K: Current advances in spinal vascular disease (article in Japanese) . Brain Nerve. 2009, 61:645-54. 